\title{
BMJ Open Changing patterns of gender inequities in childhood mortalities during the Sustainable Development Goals era in Nigeria: findings from an artificial neural network analysis
}

\author{
Daniel Adedayo Adeyinka (D) , , ${ }^{1,3}$ Pammla Margaret Petrucka, ${ }^{4}$ \\ Elon Warnow Isaac, ${ }^{5}$ Nazeem Muhajarine ${ }^{1,3}$
}

To cite: Adeyinka DA, Petrucka PM, Isaac EW, et al. Changing patterns of gender inequities in childhood mortalities during the Sustainable Development Goals era in Nigeria: findings from an artificial neural network analysis. BMJ Open 2021;11:e040302. doi:10.1136/ bmjopen-2020-040302

- Prepublication history and additional materials for this paper is available online. To view these files, please visit the journal online (http://dx.doi org/10.1136/bmjopen-2020040302).

Received 10 May 2020 Revised 25 November 2020 Accepted 17 December 2020

Check for updates

(C) Author(s) (or their employer(s)) 2021. Re-use permitted under CC BY-NC. No commercial re-use. See rights and permissions. Published by BMJ.

For numbered affiliations see end of article.

Correspondence to Dr Daniel Adedayo Adeyinka; daa929@usask.ca

\section{ABSTRACT}

Objectives In line with the child survival and gender equality targets of Sustainable Development Goals (SDG) 3 and 5, we aimed to: (1) estimate the age and sexspecific mortality trends in child-related SDG indicators (ie, neonatal mortality rate (NMR) and under-five mortality rate (U5MR)) over the 1960s-2017 period, and (2) estimate the expected annual reduction rates needed to achieve the SDG-3 targets by projecting rates from 2018 to 2030. Design Group method of data handling-type artificial neural network (GMDH-type ANN) time series.

Methods This study used an artificial intelligence time series (GMDH-type ANN) to forecast age-specific childhood mortality rates (neonatal and under-five) and sex-specific U5MR from 2018 to 2030 . The data sets were the yearly historical mortality rates between 1960s and 2017, obtained from the World Bank website. Two scenarios of mortality trajectories were simulated: (1) status quo scenarios-assuming the current trend continues; and (2) acceleration scenarios - consistent with the SDG targets. Results At the projected rates of decline of $2.0 \%$ for NMR and $1.2 \%$ for U5MR, Nigeria will not achieve the child survival SDG targets by 2030. Unexpectedly, U5MR will begin to increase by 2028 . To put Nigeria back on track, annual reduction rates of $7.8 \%$ for NMR and $10.7 \%$ for U5MR are required. Also, female U5MR is decreasing more slowly than male U5MR. At the end of SDG era, female deaths will be higher than male deaths ( 80.9 vs 62.6 deaths per 1000 live births).

Conclusion Nigeria is not likely to achieve SDG targets for child survival and gender equities because female disadvantages will worsen. A plausible reason for the projected increase in female mortality is societal discrimination and victimisation faced by female child. Stakeholders in Nigeria need to adequately plan for child health to achieve SDG targets by 2030. Addressing gender inequities in childhood mortality in Nigeria would require gender-sensitive policies and community mobilisation against gender-based discrimination towards female child.

\section{INTRODUCTION}

In recent years, there have been substantial global improvements in child survival. ${ }^{1}$ The

\section{Strengths and limitations of this study}

- This is the first known published study that used artificial neural network time series to forecast childhood mortality rates for Nigeria, which potentially makes estimates more accurate.

- To our knowledge, this is the first study that examined gender inequities in under-five mortality rates in Nigeria, with a view of providing additional information on the country's progress towards reaching the child survival and gender equality targets of Sustainable Development Goals (SDG) 3 and 5.

- Reliability test was performed to evaluate the consistency of the changing patterns of gender inequity in under-five mortality rates during SDG era.

- This study was limited in identifying trends and projecting for sex-specific neonatal mortality rates due to unavailability of sex-disaggregated neonatal data.

success has been attributed to the intensification of international and national actions targeting improvements in the major drivers of child health (eg, poverty, illiteracy, inadequate access to prenatal/postnatal care, sanitation) in resource-limited countries. Despite the reduction in mortality risks among children, most childhood deaths occur in subSaharan Africa, where 1 in 13 children died before reaching 5 years of age (ie, 76 deaths per 1000 live births) in 2017. With an underfive mortality rate (U5MR) at 100 deaths per 1000 live births in 2017, Nigeria accounted for $13 \%$ of the global burden of under-five deaths, ranked second only after India. ${ }^{1}$ The rate in Nigeria is 2.6 times the global U5MR. ${ }^{1}$

Previously, Nigeria did not achieve the Millennium Development Goal 4, which was aimed at reducing U5MR by two-thirds between 1990 and 2015. ${ }^{2}$ Further, given the problems that consistently threaten 
child survival (eg, preterm complications, pneumonia, intrapartum-related events, malaria, neonatal sepsis and diarrhoea, environmental factors and malnutrition), ${ }^{1}$ studies have reported that most countries in sub-Saharan Africa might fall short on achieving the Sustainable Development Goal 3 (SDG-3), ${ }^{3-5}$ which aims to reduce U5MR to 25 deaths per 1000 live births and neonatal mortality rate (NMR) to 12 deaths per 1000 live births by 2030 ${ }^{67}$ However, evidence on long-term trends in NMR and U5MR for Nigeria, and whether these rates are on track to meet SDG-3 targets is scanty. Also, there are study limitations based on methods used in previous studies (eg, conventional statistical methods used to model nonlinear data). ${ }^{8-10}$ In addition, no known published study has forecasted sex-specific under-five mortalities for Nigeria. Often, aggregation of forecasts obscures gender differences in childhood mortality; hence, it is difficult to monitor the country's progress towards achieving gender equality aspirations of SDG-5 by 2030, with a focus on child survival. ${ }^{11}$ While the United Nations Inter-agency Group for Child Mortality Estimation (UN-IGME) continues to generate sex-specific U5MR data, sex-disaggregated NMR is more difficult to come by. As noted by Sawyer, ${ }^{12}$ estimating mortality rates by sex introduces large sampling error arising from a small number of deaths for both sexes.

In a recent analysis of child mortality data from 195 countries, Iqbal et $a l^{13}$ concluded that girls were more likely to die within the first few years of life in low and middle-income countries (LMICs). In many regions of the world, this pattern has been attributed to gender discrimination towards the female child. ${ }^{13} 14$ Conversely, studies in Nigeria have reported male disadvantage in under-five mortality. ${ }^{15} 16$ The high mortalities among males in the early childhood stage have been attributed to biological differences between boys and girls. ${ }^{17}$ However, some authors have pointed out that there is tendency for the resource-limited countries (as in the case of Nigeria) to under-report female deaths because families are more inclined towards reporting male deaths. ${ }^{13} 14$

It is imperative to implement timely policy actions in order to close the existing inequity gaps-a critical component of SDG- 5 and SDG-10 targets. In line with the expectations of the $2014 \mathrm{UN}$ call for data revolution that would expedite sustainable development, ${ }^{18}$ this study aimed at using an artificial intelligence technique to: (1) estimate the age and sex-specific mortality trends in childrelated SDG indicators (ie, NMR and U5MR) over the 1960s-2017 period; and (2) estimate the expected annual reduction rates needed to achieve the SDG-3 targets by projecting rates from 2018 to 2030 .

\section{METHODS}

In this study, we used an artificial intelligence modelling technique, known as the deep learning technique of group method of data handling-type artificial neural network (GMDH-type ANN) algorithm, to extend the previous work of the UN-IGME. ${ }^{19}$ We analysed age-specific historical data-yearly U5MR for 1964-2017, and NMR for 1967-2017 in Nigeria (as estimated by UN-IGME). In consultation with the key stakeholders in Nigeria, the UN-IGME recalculates childhood mortality estimates based on the full birth histories, obtained from the two nationally representative surveys (ie, National Demographic and Health Survey and Multiple Indicator Cluster Survey). To ensure data comparability with other countries, the team adjusted for the dual effects of HIV and civil conflicts on child survival using Bayesian B-splines Bias-adjusted regression. The U5MRs were disaggregated by biological attribute (sex). Unlike U5MR, we could not report sex-specific NMR because of data unavailability. The data sets were obtained from the official website of World Bank. ${ }^{20}$

Prior to long-term forecasting, the aggregated historical U5MR was first implemented with autoregressive integrated moving average (ARIMA) regression, Holt-Winters exponential smoothing model, long short-term memory recurrent neural network (LSTM RNN) and GMDHtype ANN. ${ }^{21}$ This initial intermethod assessment was to determine the best forecasting technique for childhood mortality data for Nigeria. Judging by the coefficient of the intercept from Deming regression, modified NashSutcliffe efficiency coefficient model, root mean squared error (RMSE), root mean absolute error (MAE) and Diebold-Mariano test, GMDH-type ANN outperformed the conventional statistical techniques (ARIMA and HoltWinters models) and LSTM RNN. ${ }^{21}$ The comprehensive details of the different statistical methods can be found in our previous article. ${ }^{21}$

\section{Model fitting}

The artificial intelligence time series was implemented by the polynomial neuron function of GMDH-type neural network core algorithm in GMDH Shell DS V.3.8.9 software. ${ }^{22}$ The GMDH-type algorithm is a family of inductive ANNs with self-organising characteristics for modelling complex systems. ${ }^{23}$ The theoretical advantage of GMDHtype ANN over the traditional statistical method is its ability to automatically learn the pattern of data, without a priori human knowledge, hence minimising errors. ${ }^{24}$ Similar to the human brain, the ANN architecture (ie, hyperparameters) comprised large computational units-neural layers connected via synaptic weights. ${ }^{25}$ These hyperparameters had to be adequately specified when configuring neural network to reduce computational time and errors. In order to reduce forecasting errors, the neural architectures (hyperparameters) were calibrated to closely follow the methodological approach used by Banica $e t a l .^{26}$ The stopping rules were: (1) failure of the successive neural layers to further improve the model accuracy, (2) less than $1 \%$ change in testing error, and (3) saturation of layers. In selecting the number of layers and neurons, we followed the recommendations of Berry and Linoff which suggest that the number of hidden neurons should be less than twice the input layer size. ${ }^{27} 28$ The maximum number 
of network layers configured by the algorithm and initial neurons added to the layered architecture of inputs was 60 and 25, respectively. ${ }^{25}$ With this neural architecture, in-sample predictions (1960s-2017) and out-of-sample forecasting (2018-2030), along with their 95\% prediction intervals (PI), were generated for the mortality rates. The PIs were generated from the quantiles of the normal distribution of estimated standard errors.

As previous studies have noted, the validity of time series lies in data stationarity and model complexities. $^{29}{ }^{30}$ However, it is generally agreed that neural network performs better when it is trained on a number of datapoints that do not overfit (or underfit). ${ }^{29}{ }^{30}$ Also, in conformity with evidence that multivariable time series does not improve forecasting accuracy, ${ }^{31-34}$ we modelled long-term trends of NMR and U5MR with univariable time series. The built-in solver of GMDH-type algorithm ${ }^{22}$ was used for data preprocessing (removal of trend). Using the Pareto principle, ${ }^{35} 36$ the data set was randomly partitioned into training set $(80 \%)$ and testing set $(20 \%)$. We augmented the validation process by using an iterative perceptron-type procedure-polynomial neural networks of GMDH-type and RMSE-balance criteria. ${ }^{25}$ The residuals obtained from testing parts were used for model comparison. The predictive performance of the neural networks was verified with accuracy, RMSE and MAE.

\section{Estimation of changes in mortality rate trends}

We performed Mann-Kendall and Sen's slope tests to evaluate significance changes in trend. To estimate changes in trend, annual rate of reduction (ARR) was calculated as follows ${ }^{4}$ :

$$
A R R=\left(\frac{\ln \left(\frac{M R_{t+n}}{M R_{t}}\right)}{n}\right) *(-100)
$$

where $M R_{t}$ is the mortality rate for baseline year and $n$ is the number of years between the two rates. ${ }^{4}$

The ARR describes a constant rate of decline in the mortality rates between two time periods. ${ }^{4}$ To generate the expected ARR of mortality rates up to 2030 (ending of SDG era), we built two scenarios of mortality trajectories: (1) status quo scenarios-projected estimates derived from GMDH-type ANN from 2018 to 2030, assuming the current strategies and historical trend continue; and (2) acceleration scenarios-consistent with the SDG targets of 25 deaths per 1000 live births for U5MR and 12 deaths per 1000 live births for NMR by 2030 .

\section{Estimation of relative and absolute gender inequity}

The dimensions of gender inequity (ie, unfair differences in U5MR between males and females) were assessed with relative inequity and absolute inequity. ${ }^{37}$ Both relative and absolute mortality inequities were used as proxy measures for gender bias. ${ }^{13} 14$ In this paper, societal inequality connotes different forms of gender disadvantages relating to cultural norms/practices, educational and economic opportunities, civic participation, culminating in adverse health outcomes and shorter life expectancy.
The relative inequity (otherwise known as relative risk or risk ratio) was estimated as male to female sex ratio of U5MR. Sex mortality ratio is the number of male deaths per 100 female deaths in the population. The absolute inequity - an estimate of excess risk or attributable risk-was calculated as the risk difference between males and females. Sex mortality ratio $(<1)$ or negative excess mortality risk signifies gender bias unfavourable to females (ie, female disadvantage and male advantage) and vice versa. In addition, we assessed the relationship between sex mortality ratios and U5MR with Spearman's rank correlation $(r)$. As used in this study, sex refers to biological and physiological identities, while gender is a social and cultural construct.

\section{Reliability test}

To assess reliability of the changing patterns of gender inequities in child survival during SDG era, we generated a Bland-Altman plot and used Pitman's test and Lin's concordance correlation coefficient to statistically evaluate the agreement of the projected sex ratios (derived from GMDH-type ANN) with sex ratios derived from ARIMA regression. The motivation is to identify systematic differences and possible outliers of the relative magnitudes of male and female U5MR (in ratio scale) from both time series methods. According to McBride, ${ }^{38}$ agreement concordance coefficient was interpreted as: poor $(<0.90)$, moderate $(0.90-0.95)$, substantial $(0.95-$ $0.99)$ and excellent $(0.99)$. The conventional statistical analyses were implemented in Stata V.15.1 software. ${ }^{39} \mathrm{~A}$ two-sided p-value $<0.05$ and $95 \%$ CIs were used to assess statistical significance.

\section{RESULTS}

\section{Historical trends in mortality rates from 1964 to 2017}

Table 1 displays the historical mortality rates for neonates and under-five children in Nigeria. In 2017, the aggregated U5MR was 100.2 per 1000 live births-69.2\% decrease from 324.8 deaths per 1000 live births in 1964 (p trend $<0.001$ ). Also, NMR showed a significant decline$53.2 \%$, from 70.3 deaths per 1000 live births in 1967 to 32.9 deaths per 1000 live births in 2017 ( $\mathrm{p}$ trend $<0.001$ ). For the entire study period (1964-2017), NMR declined at a slower rate annually ( $\mathrm{ARR}=1.5 \%)$ compared with U5MR $(A R R=2.2 \%)$. Across the mortality indicators, rates of decline were higher between 1990 and 2017 compared with 1960s-1990 (table 1). As shown in online supplemental figure S1, age and sex-specific mortality rates in Nigeria showed a similar pattern of stepwise decline. The initial phase of decline was evidenced between 1960s and 1980s. While the rates mildly increased between early 1980s and late 1990s, the steepest decline (third phase) was observed between late 1990s and 2017.

Although males were observed to have higher U5MR than females (106.1 vs 93.8 deaths per 1000 live births), there was no substantial difference in the ARR at the end of $2017(2.2 \%$ vs $2.3 \%)$. It is striking that relative inequity 
Table 1 Historical age and sex-specific mortality rates for Nigeria, 1960s-2017

\begin{tabular}{|c|c|c|c|c|}
\hline \multirow[t]{2}{*}{ Year* } & \multicolumn{3}{|c|}{ Under-five mortality rate (per 1000 live births) } & \multirow{2}{*}{$\begin{array}{l}\text { Neonatal mortality rate (per } \\
1000 \text { live births) } \\
\text { Aggregated }\end{array}$} \\
\hline & Aggregated & Male & Female & \\
\hline 1990 & 211.9 & 222.2 & 200.9 & 50.3 \\
\hline 2017 & 100.2 & 106.1 & 93.8 & 32.9 \\
\hline 1990-2017 & $52.7 \dagger$ & $52.3 \dagger$ & 53.3† & $34.6 \dagger$ \\
\hline 1964/1967-2017 & $69.2 \dagger$ & $68.6+$ & $69.8+$ & $53.2 \dagger$ \\
\hline \multicolumn{5}{|c|}{ Annual rate of reduction (\%) } \\
\hline 1964/1967-1990 & 1.6 & 1.6 & 1.7 & 1.5 \\
\hline 1964 & 1.09 & & & \\
\hline 1990 & 1.11 & & & \\
\hline 2017 & 1.13 & & & \\
\hline \multicolumn{5}{|c|}{ Absolute mortality inequity (male-female difference)§ } \\
\hline 1964 & 27.3 & & & \\
\hline 1990 & 21.3 & & & \\
\hline 2017 & 12.3 & & & \\
\hline
\end{tabular}

*Study years: Under-five mortality rate (1964-2017) and neonatal mortality rate (1967-2017).

$\dagger$ Significant at $p$ trend $<0.001$ (Mann-Kendall and Sen's slope tests).

$\ddagger$ Relative inequity: sex mortality ratio $(>1)$ signifies gender bias unfavourable to males.

§Absolute inequity: excess risk (positive value) signifies gender bias unfavourable to males.

(as determined by sex mortality ratio) progressively worsened for males from 1.09 in 1964 to 1.13 in 2017, whereas the absolute inequity improved, with an excess male under-five mortality dropping from 27.3 per 1000 live births in 1964 to 12.3 per 1000 live births in 2017. The

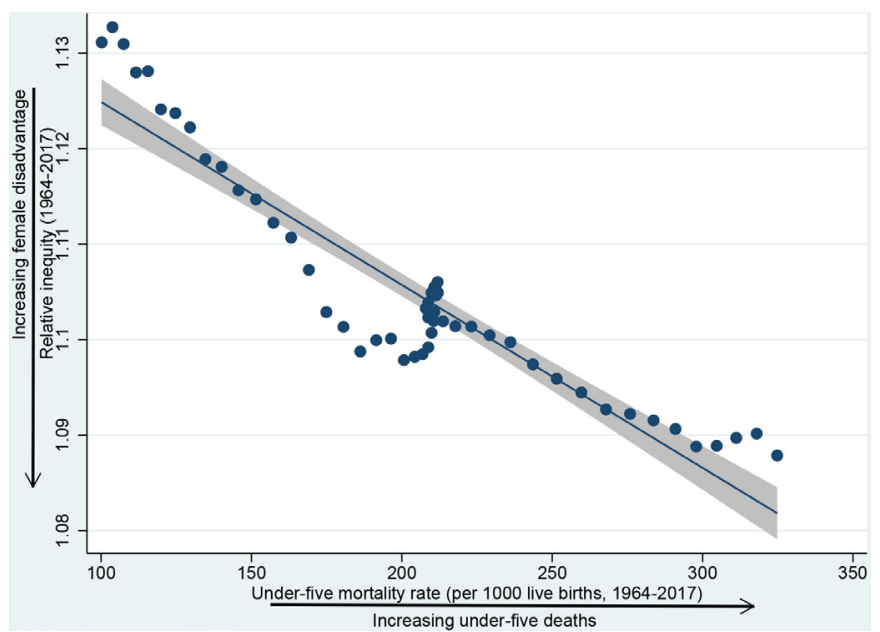

Figure 1 Relationship between relative inequities (sex mortality ratios) and under-five mortality rates, Nigeria, 19642017. influence of gender bias on under-five mortality is presented in figure 1 . There was a strong inverse correlation between relative inequities and U5MR (Spearman's $\mathrm{r}=-0.83, \mathrm{p}<0.001)$. As female mortality disadvantage increases, U5MR increases.

\section{GMDH-type ANN mortality forecasts from 2018 to 2030}

The forecasts from GMDH-type ANN time series have low error rates-RMSE (range: 0.07-0.17) and MAE (range: $0.05-0.14$ ), and high level of accuracy (range: $81.3 \%-$ $100 \%$ ) (online supplemental table S1).

\section{Scenarios of age-specific childhood mortality}

The modelled mortality rates from 2018 to 2030 for underfive and neonates are presented in figure 2A, B, respectively. The corresponding numerical estimates and the $95 \%$ PIs are shown in online supplemental table S1. From the GMDHtype ANN time series, childhood mortalities in Nigeria will continue to steadily decline but the forecasted rates will not be enough to achieve the child survival targets of SDG by 2030. With a projected ARR of $1.19 \%$ (status quo scenario), the U5MR will be 85.9 (95\% PI 85.7-86.1) deaths per 1000 live births in 2030-14.3\% decline from 100.2 deaths per 1000 live births in 2017 (figure 2A). Following the predicted trend of annual rate of 2.01\%, NMR will be 25.3 (95\% PI 25.1-25.5) 

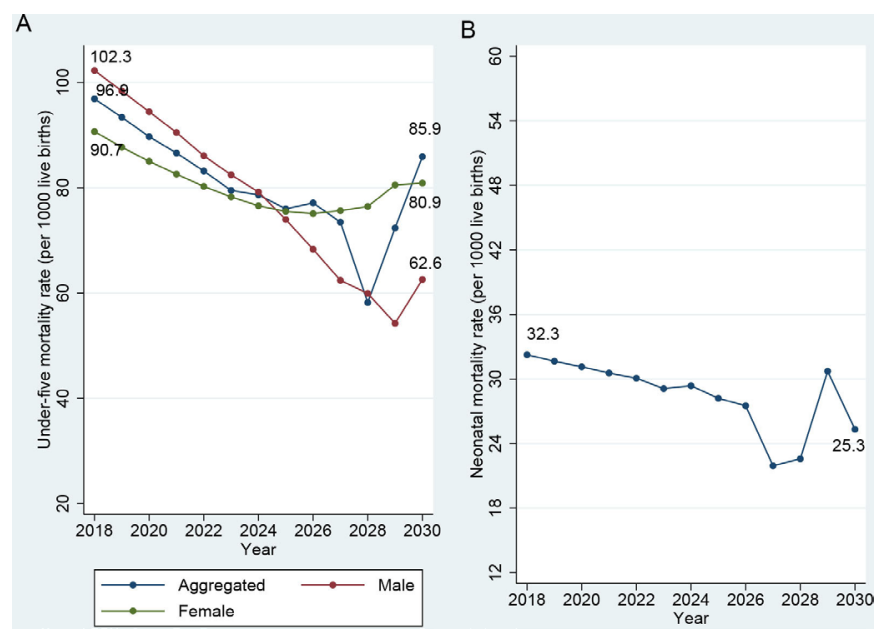

Figure 2 Long-term forecasts of group method of data handling-type artificial neural network (GMDH-type ANN) for Nigeria, 2018-2030. (A) Under-five mortality rates. (B) Neonatal mortality rates.

deaths per 1000 live births in 2030-23.1\% decrease from 32.9 deaths per 1000 live births in 2017 (figure 2B). After an initial decline between 2018 and 2027, NMR will rise steadily to peak at 30.7 deaths per 1000 live births in 2029, then it will decline to 25.3 deaths per 1000 live births by 2030 . However, U5MR will decline until 2028. Surprisingly, U5MR will rise from 2028 to 2030 (figure 2). Further analysis of mortality trajectories shows that the increasing U5MR between 2028 and 2029 is likely to be driven by the surge in the NMR during this period. However, the increasing U5MR between 2029 and 2030 could be due to rising child (1-4 years) mortality rates (online supplemental figure S2). Increasing annual rates of reduction (acceleration scenarios) of U5MR to $10.7 \%$ and NMR to $7.8 \%$ (ie, 9 and 3.9 times the rates of status quo scenario) will result in achieving the SDG-3 targets by 2030 (figure 3 ).
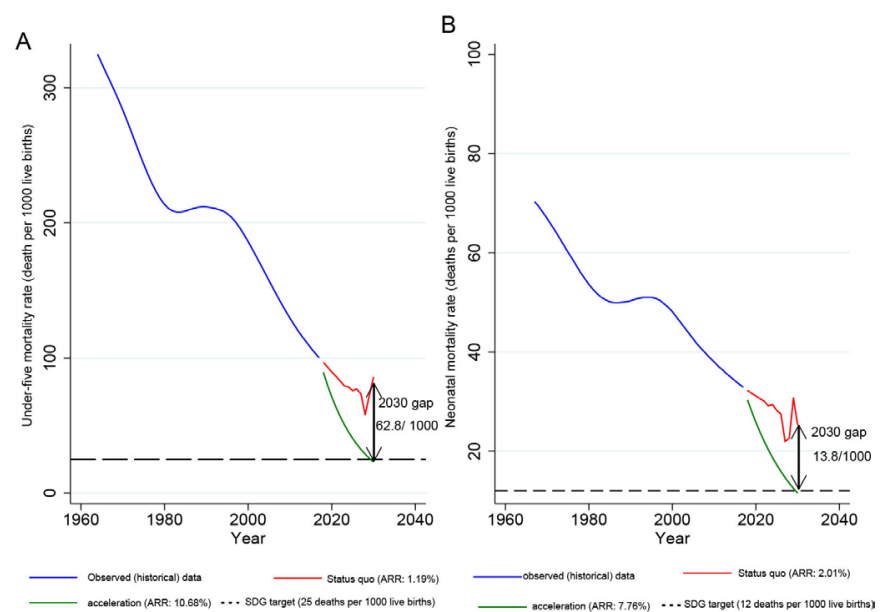

Figure 3 Projection scenarios for age-specific mortality rates, Nigeria, 2018-2030. (A) Under-five mortality rate. (B) Neonatal mortality rate. Artificial neural network (ANN) estimates were redrawn with Stata V.15.1. ARR, annual rate of reduction; SDG, Sustainable Development Goals.
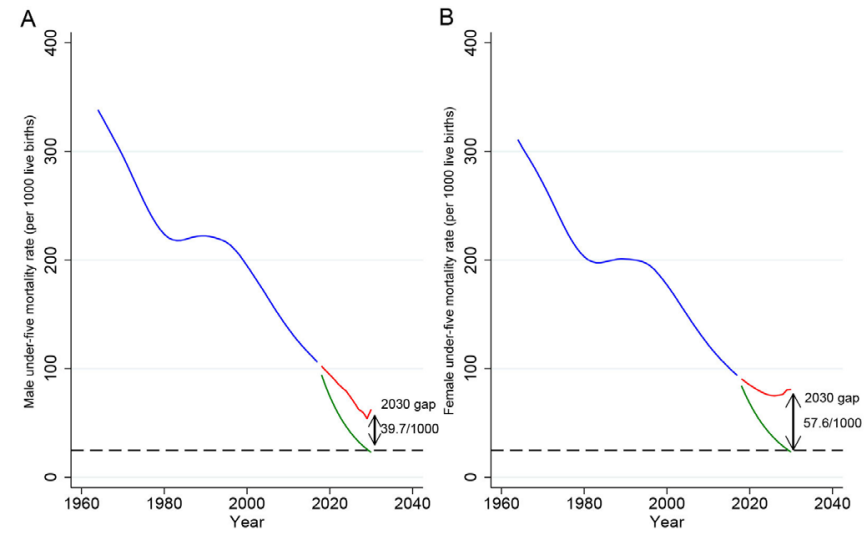

Obsenes (historical) data

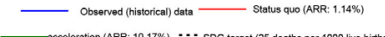

Figure 4 Projection scenarios for sex-specific mortality rates, Nigeria, 2018-2030. (A) Male mortality rate. (B) Female mortality rate. Artificial neural network (ANN) estimates were redrawn with Stata V.15.1. ARR, annual rate of reduction; SDG, Sustainable Development Goals.

\section{Scenarios of sex-specific childhood mortality}

Figure 2A shows the forecasting trend of U5MR, stratified by sex. Male and female mortality rates will decrease to 62.6 (95\% PI 62.2-62.9) deaths per 1000 live births and 80.9 (95\% PI 80.7-81.0) deaths per 1000 live births, respectively, by 2030 . In the status quo scenario, we forecasted that male U5MR will reduce at a much faster rate (ARR $=4.1 \%)$ than female U5MR (ARR $=1.1 \%$ ). The mortality rate for males will continue to be higher than the female U5MR until 2024. Remarkably, the female mortality rate will overtake male U5MR by 2025 and will steadily increase afterwards. However, male mortality rate will continue to decline until 2029, and afterwards increase. Strikingly, the unmet gap for female U5MR will be higher than male U5MR (57.6 vs 39.7 deaths per 1000 live births) by 2030 if the current trend continues. Achieving SDG targets for both sexes will only be possible with ARR of $11.1 \%$ for males and $10.2 \%$ for females (acceleration scenario) (figure 4).

Future trajectories of relative and absolute gender inequities As shown in online supplemental table S2, for the out-ofsample forecasts, the relative inequity (ratios of male to female U5MR) changed by $31.9 \%$ (1.13 in 2018 to 0.77 in 2030) and absolute inequity changed by $57.8 \%$ (11.6 in 2018 to -18.3 deaths per 1000 live births in 2030). While the relative inequity constantly rose from 1.09 in 1964, it reached its peak of male disadvantage of 1.13 during 2013-2018. The sex mortality ratios will begin to decrease (ie, increasing female disadvantage)-from 1.11 in 2020 to 0.77 in 2030. This indicates that, by 2030, 77 male deaths will occur for every 100 female deaths, unlike 113 male deaths that occurred for every 100 female deaths in 2018. Also, there has been consistent decline in excess mortality risk for males (ie, increasing absolute inequity for females) from 27.3 in 1964 to -18.3 deaths per 1000 live births in 2030 ( $\mathrm{p}$ trend $<0.001$ ). This indicates that, by 2030, 18 deaths per 1000 live births among female children will be attributed to gender bias towards the female child. These trends predict the mortality risks that Nigeria would expect to reduce U5MR with successful interventions 
by 2030 . In the same vein, for female deaths, $22.7 \%$ of the under-five mortality risk is attributable to gender bias towards female child, indicating that if gender bias towards female child could be decreased, Nigeria would expect $23 \%$ fewer under-five mortalities by 2030 .

\section{Reliability test}

From the Bland-Altman plot, Lin's concordance correlation coefficient and Pitman's test, the projected sex mortality ratios derived from GMDH-type ANN were consistent with ratios from ARIMA (online supplemental figure S3). The concordance correlation coefficient was 0.96 , suggesting substantial agreement between GMDH-type ANN and ARIMA. Furthermore, Bland-Altman plot showed $92.3 \%$ agreement. The two measurements are not statistically different as their mean difference (bias) $=-0.009, \mathrm{SD}=0.04$ and the limit of agreement $=-0.092$ to 0.075 . Thus, the changing pattern of gender inequity disfavouring female child during the SDG era is valid (Pitman's test of difference in variance: $\mathrm{r}=0.50, \mathrm{p}=0.08$ ).

\section{DISCUSSION}

Despite the need for better evidence in LMICs to guide healthcare planning and resource deployments, there remains paucity of studies on accurate forecast of yearly childhood mortality rates. Also, no known study as of date has forecasted sex-specific mortality rates to establish gender differences in childhood mortality in Nigeria. This study used an artificial intelligence method to forecast and offers rates of reducing age and sex-specific childhood mortality rates for Nigeria to achieve SDG-3 and SDG-5 targets by 2030. At the current rates of decline of $2.0 \%$ for NMR and $1.2 \%$ for U5MR, Nigeria will not achieve the child survival SDG targets by 2030. Unexpectedly, U5MR will begin to increase by 2028. However, the reasons for the upsurge in mortality rates by 2030 are not clear. The reversal in trend may be due to possible slowdown in interventions after moderate progress in reducing childhood mortality has been achieved. To put Nigeria back on track, annual reduction rates of $7.8 \%$ for NMR and $10.7 \%$ for U5MR are required. Also, female U5MR is decreasing more slowly than male U5MR. At the end of SDG era, female deaths will be higher than male deaths (80.9 vs 62.6 deaths per 1000 live births).

Across the child survival indicators, it is apparent that historical trends show slightly increased mortality rates from 1980s to 1990s, which declined afterwards. We speculate that this pattern might be related to military dictatorship and structural adjustment programmes introduced to combat economic crises in the country during this period. ${ }^{40}$ Nonetheless, we believe that it is well justified to attribute the modest decline in childhood mortality in the late 1990s to the restoration of democracy in the country. ${ }^{41}$ In line with our position, several studies have correlated improvement in population health to democracy. ${ }^{42-44}$ Some authors have also argued that military expansions (ie, spending in military and arms importation) sharply rose during the era of military dictatorship at the expense of public health spending and education. ${ }^{45-47}$ According to Golkhandan, an increment of $1 \%$ in the per-capita military expenditure is associated with $0.2 \%$ decline in the per-capita health expenditure in resource-limited countries. ${ }^{47}$ In addition to the unstable military governments coupled with human rights violations and expansions in military spending, it should also be noted that the fiscal austerity could have negatively impacted population health (as measured by U5MR) by cutting social programmes for vulnerable populations (ie, unemployed, homeless and destitute) and increasing taxes. ${ }^{48-50}$ According to Ortiz and Cummins, ${ }^{50}$ women and their children are disproportionately affected by such austerity measures in resource-limited settings. Compared with the period ruled by military, there has been an increase in total health expenditure during democratic regimes, in turn positively impacting child survival. However, investments in healthcare are mostly drawn from external sources (eg, bilateral and multilateral channels) and out-of-pocket payments. ${ }^{51}{ }^{52}$ The government investments in health have been consistently dwindling in recent years. The current government health expenditure is below the 2001 Abuja declaration of $15 \%$ annual budgetary allocation to strengthening healthcare. In a recent study, the annual health budget for Nigeria was noted to have reduced from $7.2 \%$ in 2014 to $4.4 \%$ in $2020 .^{52}$ The incessant cuts in government healthcare spending have severely affected maternal and childcare services in Nigeria. It is important to highlight that there is a progressive donor fatigue in funding population health programmes which may undermine the child survival gains in the future. ${ }^{53-55}$ We anticipate that if government continues to cut funds and there is no commitment from donors to fill the funding gaps, the year 2028 might be the potential breaking point to trigger an increase in mortality rates. As shown in our study, the projected increase in U5MR by 2028 should be a wake-up call to increase government funding to avert the anticipated future tragedy. Also, our results are consistent with research showing that societal-level gender inequalities are associated with increase in U5MR. ${ }^{56-59}$

This study confirms previous research findings that Nigeria will not achieve child survival targets of SDG-3 in 2030, at the current rate of progress. ${ }^{3}$ The U5MR and NMR will remain substantially high at 85.9 and 25.3 deaths per 1000 live births, respectively, if there are no impactful policy and programmatic actions. With Lee-Carter model, Mejía-Guevara $e t a l^{3}$ reported a slightly lower U5MR of 73 deaths per 1000 live births for Nigeria. Along this line of research, Nigri et a $f^{00}$ acknowledged superiority of neural networks (as used in this study) over the classical Lee-Carter procedure to model nonlinear data such as mortality rates. The study by Mejía-Guevara et al provided no information on the yearly progress and variability in trends for Nigeria. In this study, we provided fluctuating patterns of childhood mortality rates-an important part of mortality surveillance, and whether mortality trend will be sustained by 2030. Our results indicate downward trend in U5MR, occurring before 2028, whereas the rates are likely to increase afterwards. Likewise, there are changing patterns of sex-specific U5MR in the SDG era. As indicated by the positive values of sex differences (absolute inequity) and sex ratios (relative inequity) greater than 1 from 2018 to 
2024, there are higher male mortalities, although the trend is closing. Nevertheless, female U5MR will begin to rise steadily from 2025 to 2030 -female advantage for survival disappears. Consistent with findings from other studies, ${ }^{12}{ }^{13} 61-64$ this study suggests that under-five mortalities increased as female survival advantages decreased (ie, decreasing sex ratios). While studies have reported that under similar circumstances, females have a biological advantage than males during early childhood, the advantage disappears due to subsequent discrimination and victimisation even faced by female child. ${ }^{1261-63}$ For example, there have been concerns about the increasing cultural preference for male child in Nigeria due to social, political and economic reasons. ${ }^{65-67}$ In the same context, studies have demonstrated that health needs of girls are often neglected ${ }^{68} 69$ Evidence from Asian and African countries ${ }^{69-72}$ suggests societal discrimination against female child as evidenced by gender selective abortions (due to prenatal sex determination). ${ }^{69} 73$ According to recent reports from United Nations Human Rights Council ${ }^{74}$ and Thomson Reuters Foundation, ${ }^{75}$ Nigeria is ranked ninth among countries practising female infanticide worldwide. The female infanticide in Nigeria is carried out covertly, and often denied in communities, hence its true scale is unknown. ${ }^{76}$ However, studies have substantiated extensive practice of infanticide and male preference in Nigeria. ${ }^{65778}$ The reasons for gender discrimination and infanticide are deeply rooted in culture and traditions. Evidence suggests that male preference is dominant in Southern Nigeria, especially among Igbo communities. ${ }^{65} 7778$ Previous studies concluded that female infanticide was embraced in Nigeria because of the patriarchal considerations and sociocultural prestige. $^{657778}$

The future prospect of Nigeria to achieve child survival targets of SDG will continue to depend on inclination to accelerate annual reduction of NMR and U5MR by four and nine times the current rates, respectively. NMR is expected to decline at a relatively faster rate than U5MR (ARR: 2.0\% vs $1.2 \%$ ), hence there is an opportunity to fast-track the 12 deaths per 1000 live births target of 2030. NMR requires lesser efforts as depicted by the annual reduction rate, compared with overall U5MR ( $7.8 \%$ vs $10.7 \%)$. The practical implication of this finding is that intrapartum and neonatal services must be strengthened in Nigeria. In addition, improving neonatal survival may lead to momentous decrease in the country's U5MR. As new evidence on gender imbalance emerges from this study, the stakeholders through coordinated multidisciplinary efforts should address gender-based discrimination towards female child, while social and health needs of the males are not neglected.

Our study has several strengths. It is the first published study to our knowledge that used ANN time series to forecast childhood mortality rates for Nigeria. GMDH-type ANN provides more accurate mortality estimates. Also, this is the first known study that examined gender inequities in U5MR in Nigeria, with a view of providing additional information on the country's progress towards reaching the child survival and gender equality targets of SDG-3 and SDG-5, respectively. Given that nationally representative data were analysed, the findings are generalisable to all the regions in Nigeria.

However, our study suffered from a few limitations. There is currently no theoretical framework guiding the optimal number of neurons for building ANN architecture. ${ }^{79}$ The process hinged on implementing different simulations and selecting the models with highest performances. Although this study could not look for trend and project for sex-specific NMR due to unavailability of sex-disaggregated neonatal data, this is a desirable objective for future work. More so, disaggregating NMR by sex will provide insight about the increasing trend between 2028 and 2029, and the projected decline in neonatal deaths afterwards. The finding of female child disadvantage in child survival provides a good starting point for discourse on why this is so and what needs to be done including further research. Plurality of research methods, such as mixed methods studies, is recommended to glean insight to the complex sociocultural context influencing gender differences in U5MR during SDG era. It would also be useful to examine the variability in age and sex-specific childhood mortality trends at the subnational levels (ie, states or regions). Future research should therefore consider forecasting subnational childhood mortality rates with ANNs. The civil vital registration systems are more cost-effective platforms for continuous tracking of childhood mortality (than surveys), but presently are not reliable in Nigeria and other resource-limited settings. ${ }^{80-82}$ Civil registration in Nigeria and other resource-limited countries should be strengthened to produce accurate and reliable vital statistics data that can be used for tracking age, sex and geographic-specific mortality rates. Disaggregating childhood mortality rates by region would help identify the vulnerable populations for implementation of targeted policies and interventions.

In conclusion, our study attempts to forecast the overall and age-specific childhood mortality rates for Nigeria during the SDG era to determine where Nigeria is heading in terms of child survival and gender inequality targets of SDGs. As presented in this paper, monitoring of childhood mortality rates will allow the stakeholders to detect early, investigate and respond to any undesired outcomes related to childhood mortality trajectories. In addition, this study adds to the growing corpus of studies showing the application of artificial intelligence techniques in population health for effectively designing, planning and mobilisation of resources for child survival programmes. Our study is a further validation that Nigeria currently is not on track to achieve the SDG-3 and SDG-5 targets for NMR and U5MR. In the context of universal health coverage, gender mortality gaps among under-five children will continue to widen. This study recognises inequitable pace of progress for sex-specific mortality rates, worse for females. We highlight that U5MRs will begin to rise by 2028. Our results provide a basis for strengthening advocacy and creating more political awareness to guarantee adequate investments in child health for accelerating progress towards child survival. Addressing gender inequities in childhood mortality in Nigeria would require gender-sensitive policies and community mobilisation against gender-based discrimination towards female child. Specifically, societal gender 
inequality should be addressed by scaling up interventions such as those protecting the health and development rights of women and girls (eg, child and forced marriages, female genital cutting, female infanticide, female child education, and so on). To ensure universal health coverage, the government at all levels should prioritise health by increasing budgetary allocation to health.

\section{Author affiliations}

${ }^{1}$ Community Health and Epidemiology, College of Medicine, University of

Saskatchewan, Saskatoon, Saskatchewan, Canada

${ }^{2}$ Public Health, Federal Ministry of Health, Abuja, Nigeria

${ }^{3}$ Saskatchewan Population Health and Evaluation Research Unit, University of Saskatchewan, Saskatoon, Saskatchewan, Canada

${ }^{4}$ College of Nursing, University of Saskatchewan, Regina, Saskatchewan, Canada

${ }^{5}$ Paediatrics, College of Medical Sciences, Gombe State University, Gombe, Nigeria

Acknowledgements DAA was supported by the College of Medicine Graduate Award (CoMGRAD) from the University of Saskatchewan, Canada for his doctorate programme.

Contributors DAA conceived the study, analysed and interpreted the data, and wrote the first draft of the paper. NM contributed to the study design, edited drafts and supervised this study. NM, PMP and IE assisted with data interpretation and critically reviewed the manuscript. All authors read and approved the final manuscript.

Funding There is no specific funding for this research.

Disclaimer The content is solely the responsibility of the authors and does not necessarily reflect the official views of the University of Saskatchewan, Canada

Competing interests None declared.

Patient consent for publication Not required.

Ethics approval This study was exempted from ethical review by the University of Saskatchewan Behavioural Ethics Committee (ID number 904) as it relied on a publicly available aggregated deidentified data set.

Provenance and peer review Not commissioned; externally peer reviewed.

Data availability statement Data are available in a public, open access repository. Data set is available at the official World Bank website.

Supplemental material This content has been supplied by the author(s). It has not been vetted by BMJ Publishing Group Limited (BMJ) and may not have been peer-reviewed. Any opinions or recommendations discussed are solely those of the author(s) and are not endorsed by BMJ. BMJ disclaims all liability and responsibility arising from any reliance placed on the content. Where the content includes any translated material, BMJ does not warrant the accuracy and reliability of the translations (including but not limited to local regulations, clinical guidelines, terminology, drug names and drug dosages), and is not responsible for any error and/or omissions arising from translation and adaptation or otherwise.

Open access This is an open access article distributed in accordance with the Creative Commons Attribution Non Commercial (CC BY-NC 4.0) license, which permits others to distribute, remix, adapt, build upon this work non-commercially, and license their derivative works on different terms, provided the original work is properly cited, appropriate credit is given, any changes made indicated, and the use is non-commercial. See: http://creativecommons.org/licenses/by-nc/4.0/.

ORCID iD

Daniel Adedayo Adeyinka http://orcid.org/0000-0003-1855-6878

\section{REFERENCES}

1 UNICEF. Levels and trends in child mortality [online], 2018. Available: https://data.unicef.org/wp-content/uploads/2018/09/UN-IGMEChild-Mortality-Report-2018.pdf [Accessed 14 Mar 2019].

2 United Nations. The 2015 Millennium development goals report [online]. New York, 2015. Available: http://www.un.org/ millenniumgoals/2015 MDG_Report/pdf/MDG 2015 rev \%28July 1\% 29.pdf [Accessed 17 Oct 2018].
3 Mejía-Guevara I, Zuo W, Bendavid E, et al. Age distribution, trends, and forecasts of under-5 mortality in 31 sub-Saharan African countries: a modeling study. PLoS Med 2019;16:e1002757.

4 You D, Hug L, Ejdemyr S, et al. Global, regional, and national levels and trends in under- 5 mortality between 1990 and 2015, with scenario-based projections to 2030: a systematic analysis by the un Inter-agency group for child mortality estimation. Lancet 2015;386:2275-86 https://www.sciencedirect.com/science/article/ pii/S0140673615001208

5 Liu L, Oza S, Hogan D, et al. Global, regional, and national causes of under-5 mortality in 2000-15: an updated systematic analysis with implications for the sustainable development goals. Lancet 2016;388:3027-35

6 World Health Organization. Health in 2015: from MDGs, Millennium development goals to SDGs, sustainable development goals [online], 2015. Available: https://apps.who.int/iris/bitstream/handle/ 10665/200009/9789241565110_eng.pdf;jsessionid=EF41ECFD 78C867C3DA33E6DC9D133CC6? sequence $=1$ [Accessed 2 Mar 2019].

7 United Nations Economic and Social Council. Progress towards the sustainable development goals [online], 2018. Available: http:// unstats.un.org/sdgs [Accessed 3 Mar 2019].

8 Zhang G, Eddy Patuwo B Y, Hu M. Forecasting with artificial neural networks: the state of the art. Int J Forecast 1998;14:35-62.

9 Zhang GP. Time series forecasting using a hybrid ARIMA and neural network model. Neurocomputing 2003;50:159-75.

10 M Al-Maqaleh B, A Al-Mansoub A, N Al-Badani F. Forecasting using artificial neural network and statistics models. IJEME 2016;6:20-32.

11 United Nations. Gender equality: why it matters? [online]. Sustainable development goals. Available: http://www.un.org/ [Accessed $20 \mathrm{Apr}$ 2020].

12 Sawyer CC. Child mortality estimation: estimating sex differences in childhood mortality since the 1970s. PLoS Med 2012;9:e1001287.

13 lqbal N, Gkiouleka A, Milner A, et al. Girls' hidden penalty: analysis of gender inequality in child mortality with data from 195 countries. BMJ Glob Health 2018;3:e001028.

14 Costa JC, da Silva ICM, Victora CG. Gender bias in under-five mortality in low/middle-income countries. BMJ Glob Health 2017;2:e000350.

15 Morakinyo OM, Fagbamigbe AF. Neonatal, infant and under-five mortalities in Nigeria: an examination of trends and drivers (20032013). PLoS One 2017;12:e0182990.

16 Ezeh OK, Agho KE, Dibley MJ, et al. Risk factors for postneonatal, infant, child and under-5 mortality in Nigeria: a pooled crosssectional analysis. BMJ Open 2015;5:e006779.

17 Lawn JE, Blencowe H, Darmstadt GL, et al. Beyond newborn survival: the world you are born into determines your risk of disability-free survival. Pediatr Res 2013;74:1-3.

18 United Nations Data Revolution Group. A world that counts: Mobilizing the data revolution for sustainable development [online], 2014. Available: www.undatarevolution.org [Accessed 25 Feb 2020].

19 UN Inter-agency Group for Child Mortality Estimation. Child mortality estimates [online], 2018. Available: https://childmortality.org/ [Accessed 20 Jul 2019].

20 UN Inter-agency Group for Child Estimation. Data bank [online]. The World Bank, 2019. Available: https://data.worldbank.org/indicator/ SH.DYN.MORT?end=2017\&start=1968\&type=shaded\&view=map [Accessed $20 \mathrm{Jul}$ 2019].

21 Adeyinka DA, Muhajarine N. Time series prediction of under-five mortality rates for Nigeria: comparative analysis of artificial neural networks, Holt-Winters exponential smoothing and autoregressive integrated moving average models. BMC Med Res Methodol 2020;20:292.

22 GMDH L. GMDH shell for data science [online], 2019. Available: https://gmdhsoftware.com/signup-ds [Accessed 20 Jul 2019].

23 Farlow SJ. The GMDH algorithm of Ivakhnenko. Am Stat 1981;35:210-5.

24 Onwubolu G. GMDH-methodology and implementation in MATLAB. GMDH-methodology and implementation in MATLAB, 2016: 284.

25 GMDH Shell. Solver [online], 2017. Available: https://gmdhsoftware. com/docs/solver\#core_algorithm [Accessed 21 Sep 2019].

26 Banica L, Pirvu D, Hagiu A. Intelligent financial forecasting, the key for a successful management. Int J Acad Res Accounting, Financ Manag Sci 2012;2:192-206.

27 Berry MJ, Linoff GS. Data mining techniques. John Wiley \& Sons, 1997.

28 Xu S, Cheng L. A novel approach for determining the optimal number of hidden layer neurons for FNN's and its application in data mining. In: 5th International Conference on Information Technology and Applications, 2008: 683-6. 
29 Raudys SJ, Jain AK. Small sample size effects in statistical pattern recognition: recommendations for practitioners. IEEE Trans Pattern Anal Mach Intell 1991;13:252-64.

30 Alwosheel A, van Cranenburgh S, Chorus CG. Is your dataset big enough? Sample size requirements when using artificial neural networks for discrete choice analysis. J Choice Model 2018;28:167-82.

31 Azubuike I, Kosemoni O. A comparison of univariate and multivariate time series approaches to modeling currency exchange rate. BJMCS 2017;21:1-17.

32 du Preez J, Witt SF. Univariate versus multivariate time series forecasting: an application to international tourism demand. Int J Forecast 2003;19:435-51.

33 García-Ferrer A, Queralt RA. A note on forecasting international tourism demand in Spain. Int J Forecast 1997;13:539-49.

34 Iwok IA, Okpe AS. A comparative ctudy between univariate and multivariate linear stationary time series models. Am J Math Stat 2016;6:203-12.

35 Macek K. Pareto principle in datamining: an above-average fencing algorithm. Acta Polytech 2008;48:55-9.

36 Allen D, Hooper V. Generalized correlation measures of causality and forecasts of the VIX using non-linear models. Sustainability 2018;10:2695-46.

37 UN ESCAP. Technical working session on profiling equity focused information: ahat might an equity profile look like? [online], 2015. Available: https://www.unescap.org/sites/default/files/ TheEquityProfile.pdf [Accessed 4 May 2020].

38 McBride GB. A proposal for strength-of-agreement criteria for Lin's Concordance Correlation Coefficient [online]. NIWA Client Report: HAM2005-062, 2005. Available: http://www.medcalc.org/download/ pdf/McBride2005.pdf [Accessed 11 Jan 2020].

39 Stata version 15.1 [online], 2017. Available: https://www.stata.com/ order/ [Accessed 30 May 2019]

40 The World Bank. Nigeria Structural adjustment program policies, implementation, and impact [online], 1994. Available: http:// documents.worldbank.org/curated/en/959091468775569769/pdf/ multiOpage.pdf [Accessed $20 \mathrm{Jul} 2019]$

41 Mohamed H. News: 20 years of democracy: Has Nigeria changed for the better? [online]. Al Jazeera, 2019. Available: https://www. aljazeera.com/news/2019/06/20-years-democracy-nigeria-changed190611124203153.html [Accessed 20 Jul 2019].

42 Ruger JP. Democracy and health. QJM 2005;98:299-304.

43 Franco A, Alvarez-Dardet C, Ruiz MT. Effect of democracy on health: ecological study. BMJ 2004;329:1421-3

44 Navarro V, Borrell C, Benach J, et al. The importance of the political and the social in explaining mortality differentials among the countries of the OECD, 1950-1998. Int J Health Serv 2003;33:419-94.

45 Hou N, Chen B. Military expenditure and economic growth in developing countries: evidence from system GMM estimates. Def Peace Econ 2013;24:183-93.

46 Dommen E, Maizels A. The military burden in developing countries. $J$ Mod Afr Stud 1988;26:377-401.

47 Golkhandan A, Department of Economics, Faculty of Economics and Administrative, Lorestan University, Khorram Abad, Iran. Effect of military expenditure on health status in developing countries. Hribaq 2019;4:47-54.

48 Santos IS, Vieira FS. The right to healthcare and fiscal austerity: the Brazilian case from an international perspective. Cien Saude Colet 2018;23:2303-14.

49 Moser G, Rogers S, Van Til R. Nigeria experience with structural adjustment. Washington, 1997.

50 Ortiz I, Cummins M. Austerity measures in developing countries: public expenditure trends and the risks to children and women. Fem Econ 2013;19:55-81.

51 Hafez R. Nigeria Health financing system assessment. World Bank, 2018. Available: https://openknowledge.worldbank.org/handle/ 10986/30174

52 Adebisi YA, Umah JO, Olaoye OC, et al. Assessment of health budgetary allocation and expenditure toward achieving universal health coverage in Nigeria. Int J Heal Life Sci 2020;6:e102552.

53 Grépin KA. Efficiency considerations of donor fatigue, universal access to arts and health systems. Sex Transm Infect 2012;88:75-8.

54 Gautier L, Ridde V. Health financing policies in Sub-Saharan Africa: government ownership or donors' influence? A scoping review of policymaking processes. glob health res policy 2017;2.
55 Moszynski P. Donor fatigue is slashing access to AIDS care in Africa, warns charity. BMJ 2010;340:c2844.

56 Adeyinka DA, Olakunde BO, Muhajarine N. Evidence of health inequity in child survival: spatial and Bayesian network analyses of stillbirth rates in 194 countries. Sci Rep 2019;9:19755.

57 Abdollahpour S, Heidarian Miri H, Khademol Khamse F, et al. The relationship between global gender equality with maternal and neonatal health indicators: an ecological study. J Matern Fetal Neonatal Med 2020:1-7.

58 Marphatia AA, Cole TJ, Grijalva-Eternod C, et al. Associations of gender inequality with child malnutrition and mortality across 96 countries. Glob Health Epidemiol Genom 2016;1:1-8.

59 Brinda EM, Rajkumar AP, Enemark U. Association between gender inequality index and child mortality rates: a cross-national study of 138 countries. BMC Public Health 2015;15:97.

60 Nigri A, Levantesi S, Marino M, et al. A deep learning integrated LeeCarter model. Risks 2019;7:33.

61 Tabutin D, Masquelier B. Tendances et inégalités de mortalité de 1990 à 2015 dans les pays à revenu faible et intermédiaire. Population 2017;72:227-307.

62 Park JJ, Brondi L. Why are girls still dying unnecessarily? The need to address gender inequity in child health in the post-2015 development agenda. J Glob Health 2015;5:020303.

63 Hill K, Upchurch DM. Gender differences in child health: evidence from the demographic and health surveys. Popul Dev Rev 1995;21:127-51.

64 Drevenstedt GL, Crimmins EM, Vasunilashorn S, et al. The rise and fall of excess male infant mortality. Proc Natl Acad Sci U S A 2008;105:5016-21.

65 Nnadi I. Son Preference-a violation of women's human rights: a case study of Igbo custom in Nigeria. J Polit Law 2013;6:134-41.

66 Ohagwu CC, Ohagwu Cl, Abu PO, et al. Perception of male gender preference among pregnant Igbo women. Ann Med Health Sci Res 2014;4:178

67 Aina-Pelemo A, Saluja S. Comparative analysis of sex-Selection in Nigeria and India. IJHSSS 2018;4:71-89.

68 Khera R, Jain S, Lodha R, et al. Gender bias in child care and child health: global patterns. Arch Dis Child 2014;99:369-74.

69 UNICEF, LSTM. Gender influences on child survival, health and nutrition: a narrative review [online], 2011. Available: https://www. unicef.org/Gender_Influences_on_Child_Survival_a_Narrative_review. pdf [Accessed 3 May 2020].

70 Kaba AJ. Explaining the rapid increase in Nigeria's sex ratio at birth: factors and implications. Afr J Reprod Health 2015;19:17-33.

71 Navara KJ. Humans at tropical latitudes produce more females. Biol Lett 2009;5:524-7.

72 Sen AMissing women-revisited. BMJ 2003;327:1297-8.

73 Gupta MDSelective discrimination against female children in rural Punjab, India. Popul Dev Rev 1987;13:77-100.

74 Asian Centre for Human Rights. Female infanticide worldwide: the case for action by the UN Human Rights Council [online], 2016. Available: www.achrweb.org [Accessed 3 May 2020].

75 Thomson Reuters Foundation. The world's most dangerous countries for women 2018 [Internet], 2018. Available: https://poll2018.trust.org/ country/?id=nigeria [Accessed 6 May 2020].

76 Aneni MO. Interrogating Infanticide/ child euthanasia in the Roman Christian era, Vis-Ä-Vis the Abuja practice. Ujah J. Art Hum 2014;14:29.

77 Ohagwu C, Eze C, Eze J, et al. Perception of male gender preference among pregnant igbo women. Ann Med Health Sci Res 2014;4:173-8.

78 Nwokocha E. Male-child syndrome and the agony of motherhood among the Igbo of Nigeria. Int $J$ Sociol Fam 2007;33:219-34.

79 Aladag $\mathrm{CH}$. A new architecture selection method based on tabu search for artificial neural networks. Expert Syst Appl 2011;38:3287-93.

80 Sankoh O, Dickson KE, Faniran S, et al. Births and deaths must be registered in Africa. Lancet Glob Health 2020;8:e33-4.

81 WHO. Improving mortality statistics through civil registration and vital statistics systems strategies for country and partner support [online]. Geneva, 2014. Available: https://www.who.int/healthinfo/ civil_registration/CRVS_MortalityStats_Guidance_Nov2014.pdf?ua= [Accessed 22 Nov 2020].

82 Joubert J, Rao C, Bradshaw D, et al. Characteristics, availability and uses of vital registration and other mortality data sources in postdemocracy South Africa. Glob Health Action 2012;5:19263. 